\title{
Enfermedad de Castleman de localización mediastínica: reporte y revisión de la literatura
}

\author{
Castleman's disease of mediastinal location: \\ case report and review of the literature \\ Aldo Manuel Álvarez-Morán, ${ }^{*}$ Liliana Estefany Hernández-Navarrete ${ }^{\ddagger}$
}

\begin{abstract}
Palabras clave: Enfermedad de Castleman, tumores mediastinales, células $\mathrm{B}$, hiperplasia nodular linfoide.

Keywords: Castleman's disease, mediastinal tumors, B cells, lymphoid nodular hyperplasia.
\end{abstract}

\section{RESUMEN}

El mediastino puede ser parte de numerosas patologías, entre las que se encuentran el crecimiento de estructuras anatómicas, que van desde adenomegalias hasta tumores con diverso comportamiento histopatológico. El mediastino es un compartimento que alberga estructuras anatómicas de diferente origen embrionario y da lugar a tumores benignos que, por su crecimiento, pueden comprimir estructuras vasculares, comportándose como entidad maligna y cuya resolución quirúrgica es la única alternativa curativa. La enfermedad de Castleman es una enfermedad rara caracterizada por crecimiento linfoproliferativo de las células $\mathrm{B}$, las cuales pueden encontrarse a nivel de mediastino y cuyo tratamiento quirúrgico resulta ser una opción cuando es posible su resección. Se presenta el caso de enfermedad de Castleman localizada en mediastino, realizándose extirpación completa del tumor.

\section{ABSTRACT}

The mediastinum can be part of many pathologies, among which are the growth of anatomical structures ranging from adenomegalies to tumors with diverse histopathological behavior. Being the mediastinum a compartment which harbors anatomical structures of different embryonic origin gives rise to benign tumors that by their growth can compress vascular structures, sharing as malignant entity and whose surgical resolution is the only curative alternative. Castleman's disease is a rare disease characterized by lymphoproliferative growth of $B$ cells, which can be found at the mediastinum and whose surgical treatment is an option when resection is possible. We present the case of Castleman's disease located in the mediastinum, with complete removal of the tumor.

\footnotetext{
* Médico adscrito al Servicio de Cirugía Cardiotorácica del Hospital Ángeles Puebla. México. ¥ Médico Residente adscrito al Servicio de Cirugía General del Hospital Universitario de Puebla. México.
}

Recibido: 23/03/2019 Aceptado: 06/09/2019

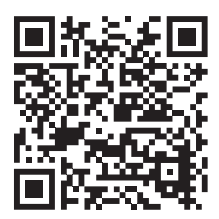

\section{INTRODUCCIÓN}

$\mathrm{T}_{\mathrm{t}}$ odas las patologías de los tumores mediastinales ocupan un número significativo de subtipos histológicos, éstos pueden ser localizados en uno u otro compartimiento mediastínico según el tipo de tejido que les de origen. La mayoría de los tumores del mediastino anterior incluyen: timomas (20\%), tumores de células germinales (15\%) y linfomas (50-70\%). Los tumores del mediastino medio en su mayoría son quistes y los más comunes son los quistes de duplicación intestinal. La mayoría de los tumores del mediastino posterior son de origen neural, y aproximadamente $80 \%$ son benignos. ${ }^{1}$
La enfermedad de Castleman (EC), descrita por primera vez por Castleman, Iverson y Menendez en 1956, es una enfermedad rara y heterogénea. Se caracteriza por el crecimiento proliferativo de las células $B$ que tiende a manifestarse con el crecimiento de tumores benignos del tejido linfático. La prevalencia de la enfermedad es desconocida, pero se ha estimado en menos de 1/100,000 habitantes. La forma localizada es la más frecuente (más de 400 casos registrados). La forma multicéntrica también puede presentarse en asociación con la infección por VIH (virus de inmunodeficiencia humana) y puede manifestarse a cualquier edad. La frecuencia de los síntomas ha sido evaluada en una cohorte francesa de 117 ca-

Citar como: Álvarez-Morán AM, Hernández-Navarrete LE. Enfermedad de Castleman de localización mediastínica: reporte y revisión de la literatura. Cir Gen. 2020; 42 (4): 321-325. https://dx.doi.org/10.35366/101403 
sos. Las formas localizadas son asintomáticas en $51 \%$ de los pacientes y a menudo se han descubierto por casualidad. Pueden provocar dolor en tórax o abdomen cuando la lesión es grande (diámetro medio de $6 \mathrm{~cm}$ con extremos que oscilan entre 1 y $12 \mathrm{~cm}$ ). ${ }^{2}$ Los sitios afectados, por orden de frecuencia decreciente, son: abdomen, ganglios linfáticos superficiales y mediastino. Los signos son inespecíficos en $31 \%$ de los pacientes e incluyen: astenia (20\%), fiebre $(20 \%)$ y pérdida de peso $(11 \%)$. Las formas multicéntricas son siempre sintomáticas. La pérdida de peso se produce en $69 \%$ de los pacientes y la fiebre en $67 \%$. En $81 \%$ de los casos se observa linfadenopatía periférica, hepatomegalia y/o esplenomegalia en $74 \%{ }^{3}$

La enfermedad localizada se observa con mayor frecuencia en la condición abdominal o pélvica, mientras que las formas diseminadas se observan con nódulos superficiales o localización mediastínica. ${ }^{4}$ La enfermedad de Castleman, también conocida como hiperplasia nodular linfoide angiofolicular o hiperplasia nodular linfoide, es una entidad interesante debido a su peculiar forma de presentación clínica y a la baja frecuencia que se produce y se presenta en la población. ${ }^{3}$ El lugar en el que se presenta la enfermedad puede ser cualquiera en donde existan ganglios linfáticos o también puede ser en un sitio extranodal.

Esta enfermedad no tiene ninguna predilección del género y suele ocurrir entre la segunda y tercera décadas de la vida, con una ocurrencia rara en niños menores de 13 años. Se han descrito tres tipos histológicos: vascular hialina $(90 \%)$, células plasmáticas y la forma mixta (10\%). En su patogenia se ha asociado a procesos infecciosos, expresión anormal de citocinas o autoinmunidad que puedan causar proliferación linfoide. ${ }^{4,5}$

El virus del herpes 8 (HV-8) se ha asociado con el sarcoma de Kaposi, el linfoma no Hodgkiniano y variedad plasmática de la enfermedad del Castleman de tipo multicéntrico. ${ }^{6-11}$ En esta enfermedad, parece haber sobreproducción de interleucina-6 (IL-6), la cual se ha relacionado con la expresión de células plasmáticas. ${ }^{11-13} \mathrm{El}$ tipo vascular hialino no se ha vinculado con trastornos mediados por citosinas, y ésta es de localización regional (80-90\% de los casos), generalmente asintomática. Los casos de EC son sintomáticos cuando su tamaño es muy grande y producen compresión de estructuras anatómicas circundantes. La variedad plasmática y la forma mixta representan $10-20 \%$ de los casos localizados. ${ }^{5,7,8}$ La variedad de células plasmáticas se manifiesta comúnmente como una enfermedad diseminada relacionada con la hepatoesplenomegalia (70-80\% de los casos); se asocia con manifestaciones sistémicas, pérdida de peso, polineuropatía, insuficiencia renal o hepática, en otros casos con poliartritis o glomerulonefritis, hipergammaglobulinemia, leucopenia, trombocitopenia, hipoalbuminemia y proteinuria. ${ }^{4-6}$ El diagnóstico de la enfermedad se basa en la evaluación clínica que incluye una historia detallada del paciente, estudios de laboratorio y una variedad de estudios de imagen como la tomografía computada, proyección de imagen de resonancia magnética, tomografía de la emisión del positrón. Este último es útil ya que nos da información sobre la actividad metabólica de los nódulos linfoides, aunque los valores de atenuación son más bajos que los observados en los linfomas. ${ }^{11,12,14}$

La extirpación quirúrgica es el tratamiento de elección en la mayoría de los casos localizados con compromiso de estructuras vecinas. En la actualidad, se dispone de técnicas mínimamente invasivas para su extirpación como la cirugía torácica videoasistida (VATS) y la cirugía robótica (Da Vinci), cuyos resultados son excepcionalmente buenos en el periodo postoperatorio en la recuperación de los casos, y en donde además se puede realizar una extirpación completa y vaciamiento mediastinal. ${ }^{15}$ Los esteroides adyuvantes y/o Rituxan antes de la cirugía son útiles para disminuir el tamaño tumoral. ${ }^{5-7}$ Un gran número de terapias se han utilizado en la enfermedad multicéntrica tales como inmunoglobulinas, aciclovir, ganciclovir y quimioterapia de la combinación como el CHOP. Otras terapias incluyen el uso de inhibidores angiogénicos del crecimiento. Las terapias anti-IL-6 incluyen la Suramin y anticuerpos antirreceptores de IL-6.5,12

\section{INFORME DEL CASO}

Se trata de un hombre de 47 años que había sido manejado desde hace 15 años por presentar gota, por lo que acude a consulta de 
reumatología, en donde refiere sintomatología respiratoria de tres meses de evolución caracterizado por tos seca en accesos, además de edema facial y extremidades superiores. Durante la revisión solicitó la radiografía rutinaria de tórax, encontrando ensanchamiento mediastínico, por lo que se realiza topografía computada, en la cual se evidencia masa en mediastino medio de aproximadamente $7 \times 5$ centímetros en diámetro, con compresión extrínseca de la vena cava superior y vena ácigos, elevación del hemidiafragma homolateral, además de hepatomegalia severa (Figura 1).

Los resultados del laboratorio demostraron: hemoglobina $15 \mathrm{~g} / \mathrm{dl}$, hematocrito $48.2 \%$, leucocitos 7,800 por microlitro, plaquetas 182,000, tiempo de protrombina 10 segundos, International Normalized Ratio (INR) 0.77, tiempo parcial de tromboplastina 29.5 segundos, glucosa $82 \mathrm{mg} / \mathrm{dl}$, urea 11.5, ácido úrico $8.3 \mathrm{mg} / \mathrm{dl}$, linfocitos 3\%, pruebas de función hepática en parámetros normales. Pruebas serológicas para $\mathrm{VIH}$ negativas.

Se realiza toracotomía posterolateral derecha debido a que no contamos con equipamiento para realizar cirugía mínimamente invasiva, encontrando tumor en mediastino medio de aproximadamente $7 \times 5 \times 4 \mathrm{~cm}$, consistencia dura, encapsulado, adherido a la pared lateral a la vena cava superior, borde superior de la vena ácigos y tráquea intratorácica, y a su porción más baja a la vena de ácigos (Figura 2). El tumor fue extirpado en su totalidad (Figura 3). En el

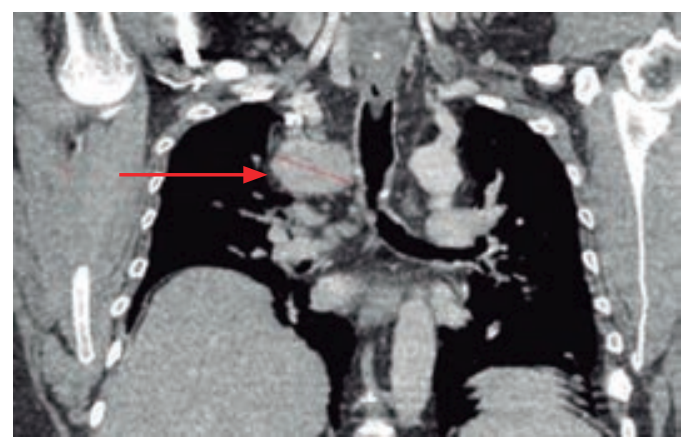

Figura 1: Masa en mediastino medio (flecha roja) de aproximadamente $7 \times 5 \mathrm{~cm}$ en diámetro, con compresión parcial de la vena cava superior, con elevación del hemidiafragma derecho, además de hepatomegalia severa con esteatosis.

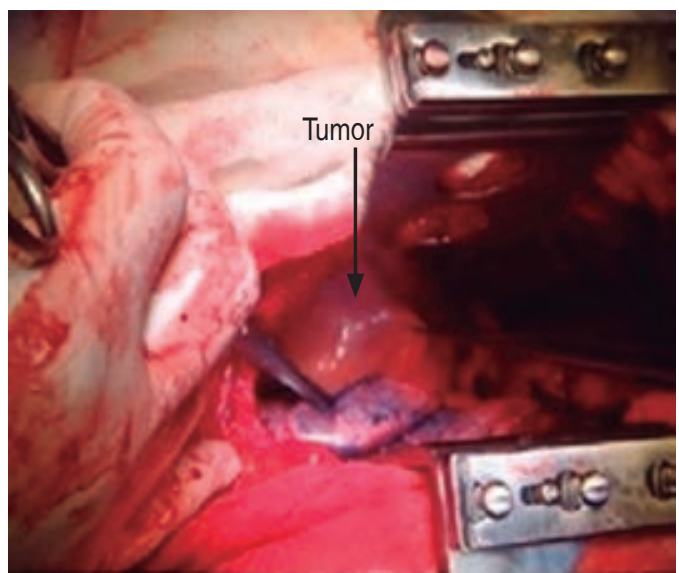

Figura 2: El tumor en el mediastino medio (flecha negra) unida la pared lateral a la vena cava superior y la tráquea, y su porción más baja a la vena ácigos.

periodo postoperatorio inmediato, el paciente es egresado sin ninguna complicación y extubado, el control radiológico demostró expansión pulmonar completa (Figura 4).

Durante la evaluación de la histopatología macroscópicamente se remite como tumor encapsulado con escaso tejido fibroadiposo adherido con finos trayectos vasculares. Refiriendo diagnóstico histopatológico como enfermedad de Castleman tipo hialino vascular, con hiperplasia reactiva de las células dendríticas con panel de anticuerpos realizados para CK AE1/AE3 negativos y CD21 positivos.

El paciente fue egresado por mejoría al tercer día del postoperatorio, con seguimiento en la consulta de hematología y reumatología, con un ciclo corto de esteroides. Durante seguimiento por un año sin evidencia tomográfica de masas a nivel de mediastino medio.

\section{DISCUSIÓN}

La enfermedad de Castleman es rara y se caracteriza por el crecimiento proliferativo de células B que tiende a manifestarse con tumores benignos del tejido linfático, los cuales, debido a su crecimiento, pueden causar compresión de estructuras vecinas. Es una entidad interesante debido a su peculiar forma de presentación clínica y a la baja frecuencia que se produce y se presenta en la población. ${ }^{1,2}$ La enfermedad se puede presentar en cualquier lugar en donde 
existan ganglios linfáticos o también puede ser en un sitio extranodal.

Algunos autores describen las formas localizadas en $70 \%$ a nivel abdominal o pélvica, seguidos de la localización torácica, mientras que las formas diseminadas se observan con nódulos superficiales o localización mediastínica. Cabe destacar este caso, ya que se trató de una enfermedad ubicada a nivel de mediastino que, por su localización, es rara, como síntomas produjo compresión de vena cava superior, manifestando edema facial y de extremidades superiores, además de sintomatología respiratoria vaga.

Si la enfermedad de Castleman se encuentra localizada, debe realizarse la extirpación quirúrgica completa y es necesario un seguimiento posterior, como sucedió en el caso que presentamos. Desde el punto de vista clínico, la sintomatología con la que se presentó fue inespecífica, lo cual nos orientó hacia la resección quirúrgica como tratamiento. Como hemos mencionado, en la actualidad disponemos de técnicas mínimamente invasivas como la cirugía torácica videoasistida y robótica (Da Vinci), cuyos resultados son equiparables a la cirugía convencional, pudiéndose realizar una extirpación completa del tumor y vaciamiento ganglionar en mediastino, ofreciendo mejores resultados en la recuperación postoperatoria de los pacientes, por lo que se han convertido en las técnicas de elección para la extirpación quirúrgica de estos tumores en aquellos centros

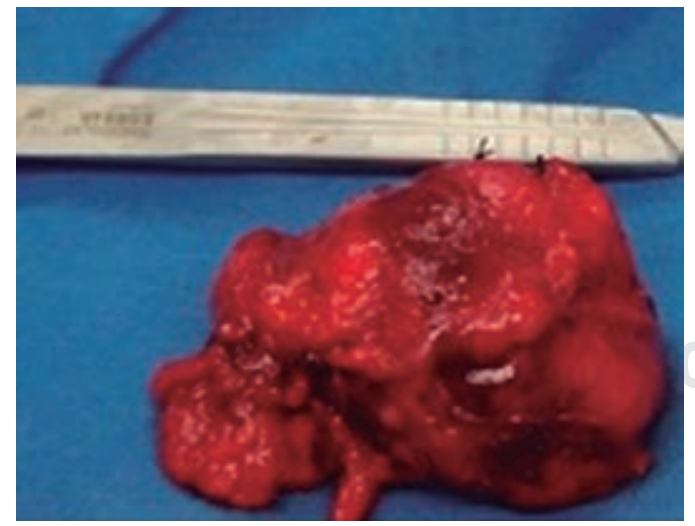

Figura 3: La tumoración resecada en su totalidad midió aproximadamente $7 \times 5 \times 4 \mathrm{~cm}$, de consistencia dura y bien encapsulada.

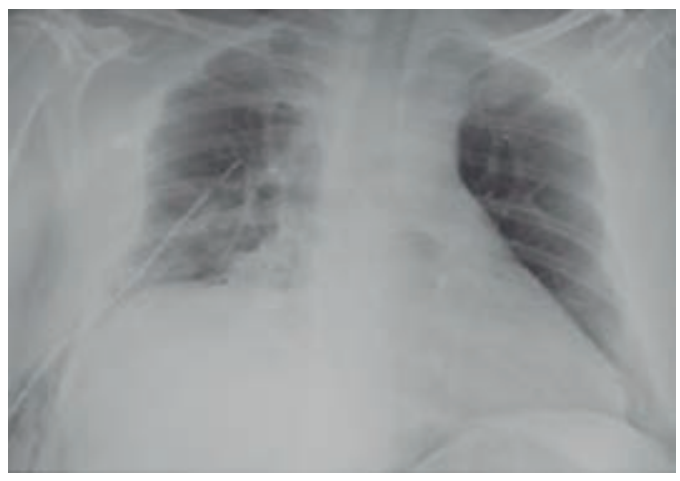

Figura 4: La radiografía postoperatoria mostró expansión pulmonar completa.

hospitalarios en donde se tenga este recurso disponible.

Otro aspecto importante para considerar en la EC multicéntrica es su asociación con $\mathrm{VIH}$, por lo que se deben realizar las pruebas correspondientes, así como una inmunotinción para excluir un linfoma, las cuales en nuestro paciente resultaron ser negativas. En lo que respecta al estudio histopatológico, se trató del tipo vascular hialino y, como se describe en la literatura, es de localización regional (80-90\% de los casos), por lo general asintomática. Los casos de enfermedad de Castleman son sintomáticos cuando su tamaño es muy grande y producen compresión de estructuras anatómicas circundantes. ${ }^{5,7,8}$ La variedad de células plasmáticas se manifiesta comúnmente como una enfermedad diseminada relacionada con la hepatoesplenomegalia, lo cual no corresponde a este caso.

En cuanto al tratamiento no quirúrgico, se han propuesto diferentes tipos de poliquimioterapias, tales como el régimen $\mathrm{CHOP}$ (ciclofosfamida, doxorrubicina, vincristina y prednisona), que ha tenido éxito; el IFN-alfa, solo o en combinación con vinblastina o etopósido, ha demostrado ser beneficioso en algunos casos. El anticuerpo monoclonal anti-IL-6 se puede utilizar. $^{13,14}$

\section{CONCLUSIÓN}

En las formas localizadas de EC, la recuperación sin secuelas tras la extirpación quirúrgica completa se alcanza en $90 \%$ de los casos, en 
donde las técnicas mínimamente invasivas, como VATS y Da Vinci, son los procedimientos de elección cuando están disponibles en el centro hospitalario. La EC es una enfermedad rara, pero su presentación anatomoclínica puede limitarse a mediastino $y$, debido a su crecimiento, puede en un momento determinado comprimir estructuras vasculares y parte de la vía aerodigestiva, lo cual nos debe hacer pensar en esta entidad como una posibilidad Clínica. El tratamiento quirúrgico está indicado con seguimiento subsecuente de los casos por la probable recidiva de la enfermedad. Además, siendo el mediastino un compartimento anatómico de diferentes estructuras con origen embrionario diferente, nos debe hacer sospechar no nada más de las patologías que usualmente se presentan en este compartimento anatómico.

\section{REFERENCIAS}

1. Ibarra-Pérez C, Kelly-García J, Fernández-Corzo MA. Guía diagnóstico-terapéutica: tumores y masas del mediastino. Rev Inst Nal Enf Resp Mex. 2001; 14: 172-177.

2. Orphanet. Enfermedad de Castleman. 2014 [consultado 31 de enero 2019]. Disponible en: https://www.orpha.net/consor/cgi-bin/OC_Exp. php?lng $=$ ES\&Expert $=160$

3. Castleman B, Iverson L, Menendez VP. Localized mediastinal lymphnode hyperplasia resembling thymoma. Cancer. 1956; 9: 822-830.

4. Palestro G, Turrini F, Pagano M, Chiusa L. Castleman's disease. Adv Clin Path. 1999; 3: 11-22.

5. Shroff VJ, Gilchrist BF, DeLuca FG, McCombs HL, Wesselhoeft CW. Castleman's disease presenting as a pediatric surgical problem. J Pediatr Surg. 1995; 30: 745-747.

6. Martino G, Cariati S, Tintisona O, Veneroso S, De Villa F, Vergine $M$, et al. Atypical lymphoproliferative disorders: Castleman's disease. Case report and review of the literature. Tumori. 2004; 90: 352-355.
7. Weisenburger DD, Nathwani BN, Winberg CD, Rappaport H. Multicentric angiofollicular lymph node hyperplasia: a clinicopathologic study of 16 cases. Hum Pathol. 1985; 16: 162-172.

8. Keller AR, Hochholzer L, Castleman B. Hyaline-vascular and plasma-cell types of giant node hyperplasia of the mediastinum and other locations. Cancer. 1972; 29: 670-683.

9. Lachant NA, Sun NC, Leong LA, Oseas RS, Prince HE. Multicentric angiofollicular lymph node hyperplasia (Castleman's disease) followed by Kaposi's sarcoma in two homosexual males with the acquired immunodeficiency syndrome (AIDS). Am J Clin Pathol. 1985; 83: 27-33.

10. Pavlidis NA, Skopouli FN, Bai MC, Bourantas CL. A successfully treated case of multicentric angiofollicular hyperplasia with oral chemotherapy (Castleman's disease). Med Pediatr Oncol. 1990; 18: 333-335.

11. Staskus KA, Sun R, Miller G, Racz P, Jaslowski A, Metroka C, et al. Cellular tropism and viral interleukin-6 expression distinguish human herpesvirus 8 involvement in Kaposi's sarcoma, primary effusion lymphoma, and multicentric Castleman's disease. J Virol. 1999; 73: 4181-4187.

12. Renne R, Lagunoff M, Zhong W, Ganem D. The size and conformation of Kaposi's sarcoma-associated herpesvirus (human herpesvirus 8) DNA in infected cells and virions. J Virol. 1996; 70: 8151-8154.

13. Staskus KA, Zhong W, Gebhard K, Herndier B, Wang $H$, Renne R, et al. Kaposi's sarcoma-associated herpesvirus gene expression in endothelial (spindle) tumor cells. J Virol. 1997; 71: 715-719.

14. Parravicini C, Corbellino M, Paulli M, Magrini U, Lazzarino M, Moore PS, et al. Expression of a virusderived cytokine, KSHV vIL-6, in HIV-seronegative Castleman's disease. Am J Pathol. 1997; 151: 15171522.

15. Quevedo AK, Aragón JC, Mancheño FN, Sales BG, Medina CV, García ZA, et al. Enfermedad de Castleman: dos variantes, dos pacientes. Revista de Patología Respiratoria. 2011; 14: 138-142.

Correspondencia:

Dr. Aldo Manuel Álvarez-Morán

Avenida Kepler Núm. 2143,

Reserva Territorial Atlixcáyotl, 72190, Puebla, Puebla.

Tel: (222) 2143534, ext. 3101

E-mail: mdald73@hotmail.com 